\title{
INVESTIGATION OF AERODYNAMIC INTERFERENCE IN A MULTIROTOR BY PIV METHOD
}

\author{
Zbigniew Czyż', Wit Stryczniewicz ${ }^{2}$ \\ 1 Department of Thermodynamics, Fluid Mechanics and Aviation Propulsion Systems, Faculty of Mechanical \\ Engineering, Lublin University of Technology, Nadbystrzycka 36, 20-618 Lublin, Poland \\ 2 Institute of Aviation, Aerodynamics Department, Krakowska 110/114, 02-256 Warsaw, Poland \\ * Corresponding author's e-mail: z.czyz@pollub.pl
}

Received: 2017.06 .25

Accepted: 2018.02.01

Published: 2018.03.01

\begin{abstract}
:
This paper presents part of the investigation into aerodynamics of the vertical take-off and landing multirotor. There are described the technology to design a research object and the Particle Image Velocimetry (PIV) setup to measure airflow around the aircraft. The around-the-aircraft speed distribution was investigated for an angle of attack of $0^{\circ}$ and for four different configurations. The results are presented in form of vector velocity field of airflow on the plane of symmetry of the test object. The results enabled the characteristics of speed vs. the distance from the fuselage. It was observed that the push propeller and the main rotor impact the speed field around the fuselage.
\end{abstract}

Keywords: aerodynamics, wind tunnel, wind tunnel research, Particle Image Velocimetry (PIV).

\section{INTRODUCTION}

There are attempts to create advanced, competitive and safe aircraft, and their production and use should be economical, too. The aspects of their ecological operation, especially toxic emissions and noise cannot be ignored. All of these assumptions require aircraft designers' extraordinary effort, a wide range of calculations and broad investigation. Many aircraft designers regard gyroplanes as future and innovative solutions. Although their design assumptions and principle of operation do not make them modern and innovative aircraft, it is a dynamic development of this type of aviation that creates opportunities for constructing an unmatched and widely applicable aircraft with excellent performance. Therefore, the basic gyroplane construction should be completed with some extra systems, equipment, installations, aggregates, and especially design components to make it distinguishable among the standard aircraft.
First of all, the gyrocopter should be able to take-off vertically and even hover. Another important criterion is achieving high cruise speed without breaching main rotor noise standards. Following the above objectives, we are able to design a gyroplane of parameters better than the helicopter and that is unrivaled for aircraft.

Logically and practically, the advantages of gyroplanes and increasingly popular multicopters should be combined to design a fast and quiet type of aircraft capable of vertical take-off and landing. Such an aircraft may turn out to be economical, safe and able to perform tasks typical for standard aircraft.

The demand for power in multicopters adversely increases when they change from hover to horizontal flight, or when their speed increases. It is possible to reduce their energy consumption by unloading the drive unit during flight by unpowered rotor in autorotation. Autogyros show lower energy consumption during flight than helicopters and even more than multirotors [6] (Fig. 1). 
Accordingly, it is sensible to combine the advantages of the autogyro as a lightweight, simple and economical design with a multirotor system capable of shortened take-off or vertical takeoff and landing, low-speed flight stability and improved safety. The combination of these two types of aircraft brings about an innovative means of personal air transport. Figure 2 shows its exemplary visualization. The premises behind the concept of such an aircraft are described in [4].

Today's research into aircraft aerodynamics relies on many techniques of measurement and calculation of volatile properties and phenomena that occur in the airflow around the aircraft. One of the most important trends is combining experimental wind tunnel research and numerical computation. For example, incorporation of numerical computation techniques like Computational Fluid Dynamics (CFD) in the experimental wind tunnel investigation already at the design stage enable us to evaluate design objectives and avoid an expensive creation of test bench models or prototypes [1] [3]. Advanced CFD tools enable us, e.g. to create aerodynamic characteristics or to visualize parameters like fields of speed, pressure, temperature around the test object. Since the aerospace research began, flow visualization has been used to explain phenomena that occur in all phases of flight. At present, one of the most common methods is Particle Image Velocimetry (PIV). This optical method enables qualitative visualization and quantitative measurement of speed of flow, e.g. airflow around the test object. So a vector field of instantaneous velocity can be created to describe phenomena that occur during the measurement. The flow is seeded with particles. If particles in the main fluid are relatively small and neutrally buoyant, they are assumed to precisely follow the flow dynamics and pathlines. The fluid with small particles is highlighted so that particles are clearly visible on a single plane. Nowadays, PIV analysis is based on cross-correlation of taken images of particles suspended in the fluid. The digital analyses provide a quantitative, $2 \mathrm{D}$ image of flow with defined local values of velocity and direction of flow. PIV is now frequently used in both fundamental and commercial aerodynamic low and high speed research. For example, the technique was applied for investigations of a vortex ring state of main rotor of a helicopter [11]. PIV is also successfully applied for fundamental studies i.e. [14] shows the research into time and spatial scale of turbulence by high frequency resolution PIV method. The paper [2] and [10] present the PIV-based research into transonic and supersonic flow where a precise determination of shock position and shape is important. The calibration wind tunnel nozzle of a with Mach numbers of 3.5 and 4.5 were performed in [5]. Application of advanced high speed and high spatial resolution PIV systems allow to investigate complex flow phenomena [12]. Improvements of PIV systems performance result from advances in laser and information technologies which allow for applying advanced algorithms to process images [7] [11] [13]. This paper describes how PIV method can

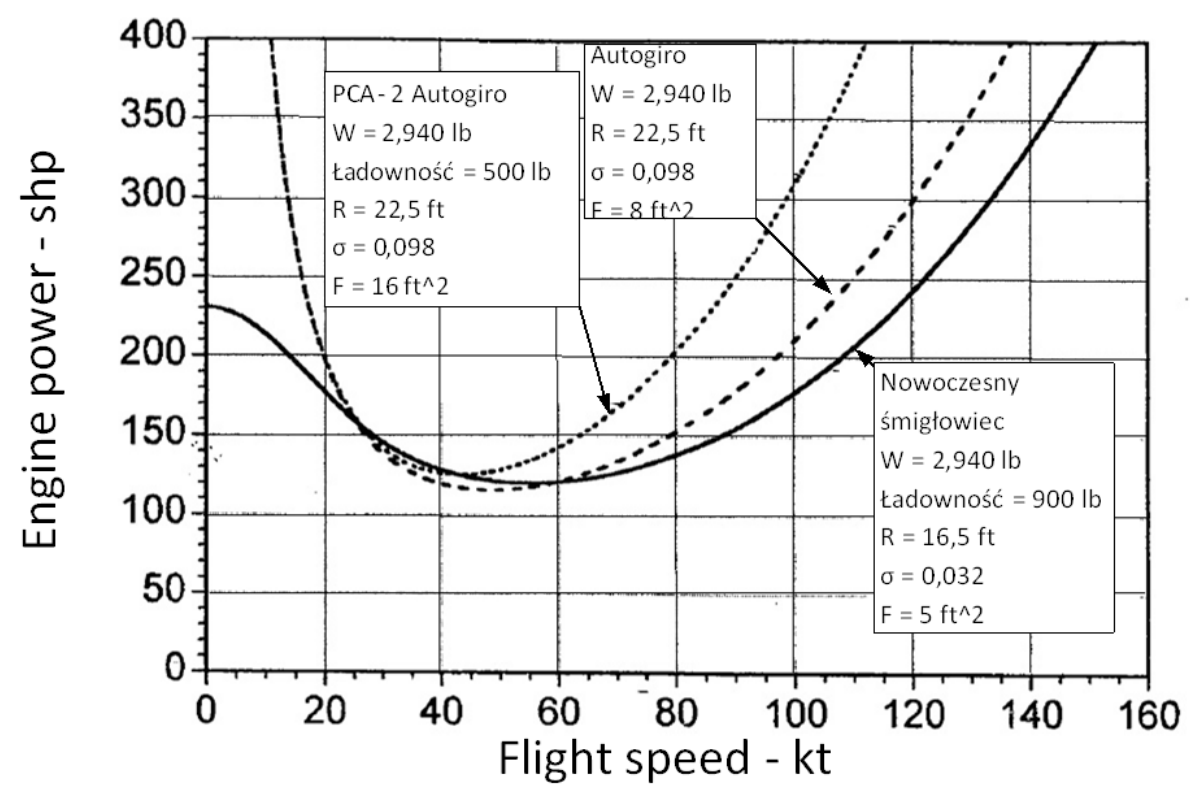

Fig. 1. Demand for power in autogyros and helicopters, based on [6] 


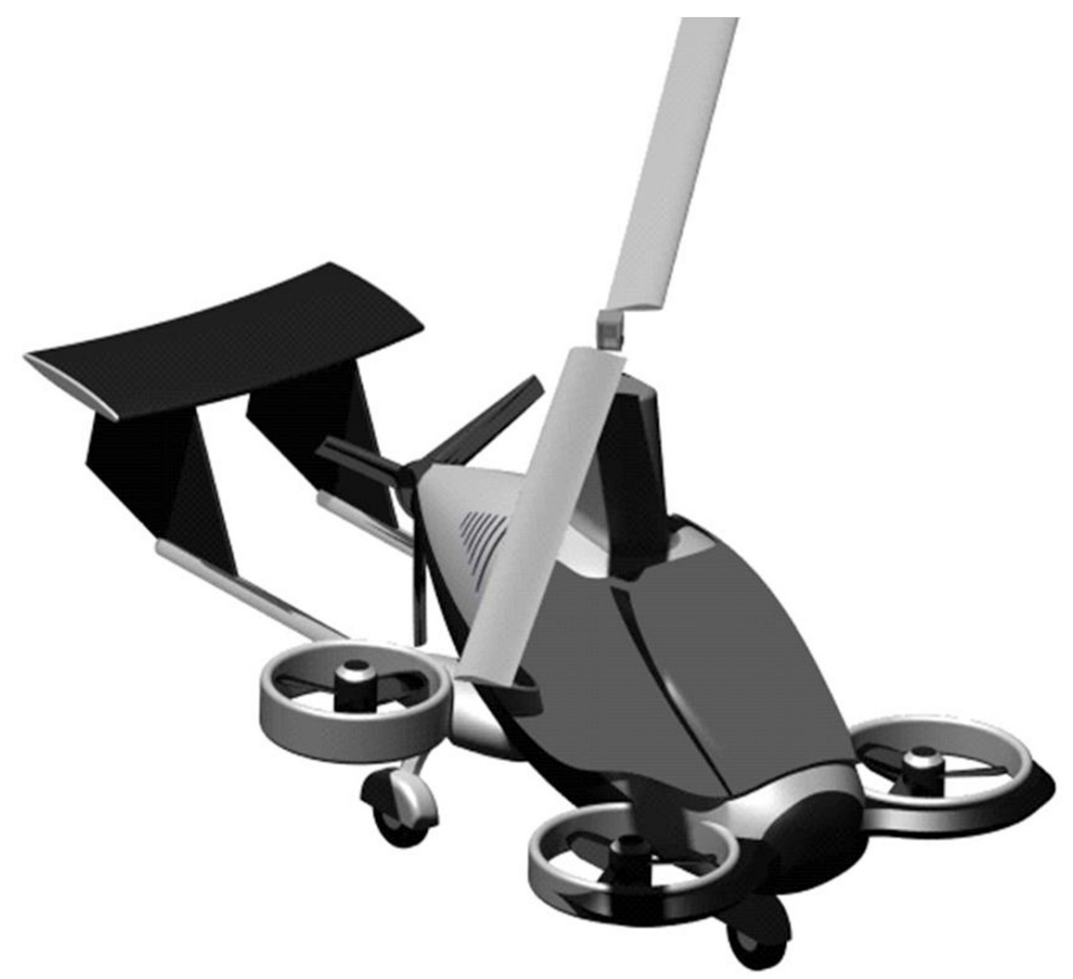

Fig. 2. Visualized concept of a hybrid multirotor aircraft

be applied to define aerodynamic interference of flows generated by rotors in an innovative multirotor. Our research results enable a new construction to be optimized.

\section{RESEARCH OBJECT}

There are many researches into unpowered rotor in autorotation but few only into interference of extra power sources on main rotor operation. Aerodynamic interference is all more complex in the construction shown in Figure 2. To be wind tunnel investigated, the research object is based on a real autogyro, i.e. the Taifun by Aviation Artur Trendak. Received from the manufacturer, a 2D model was converted to a 3D model. Before this conversion, a scale was defined as 1:8 to enable measurements in wind tunnel T-1 at the Aviation Institute in Warsaw. The so scaled real aircraft has a main rotor of $1.1 \mathrm{~m}$. Later, this 3D model was separated into its components, which is necessary due to a physical capability of a $3 \mathrm{D}$ printer and the later installation of the autogyro on a strain gauge scales. The aircraft is separated into three sections, i.e. the fuselage front, the fuselage rear and the tail, see Fig. 3. The tail was also separated into two sections, right and left, to laminate them easily.
Inside the the fuselage, there are mounting and fixing elements for installing there a tensiometric balance and profiles for extra drive units. The mounting elements are designed so that they occupy the least area inside the fuselage but still are able to release the largest loads due to resistance or propeller drag forces. The fixing elements are accompanied by the special holes for aluminum profiles to be installed inside the aircraft and to install extra drive units. The holes for the aluminum profiles are $5 \mathrm{~mm}$ by $20 \mathrm{~mm}$. Figure 4 shows the interior of the fuselage with the mounting and fixing elements.

The next part of the research to create a 3D model focused on making an internal frame. This element enables a strain gauge scales to be installed and both fuselage sections to be joined. The frame is made from sheet metal and aluminum tubes. It is lightweight but supports the construction well. The aircraft model has been printed in a 3D powder printing technology in line with the previously created digital model. The printing proceeded in 3 stages, so first a stabilizer was printed, then a fuselage front and finally a fuselage rear. Generally, printing is preceded by importing a file of a digital model and correctly placing a printed element in a printer compartment. Our printer is the ZPrinter 450. The total printing time of each element was 10 hours. The 

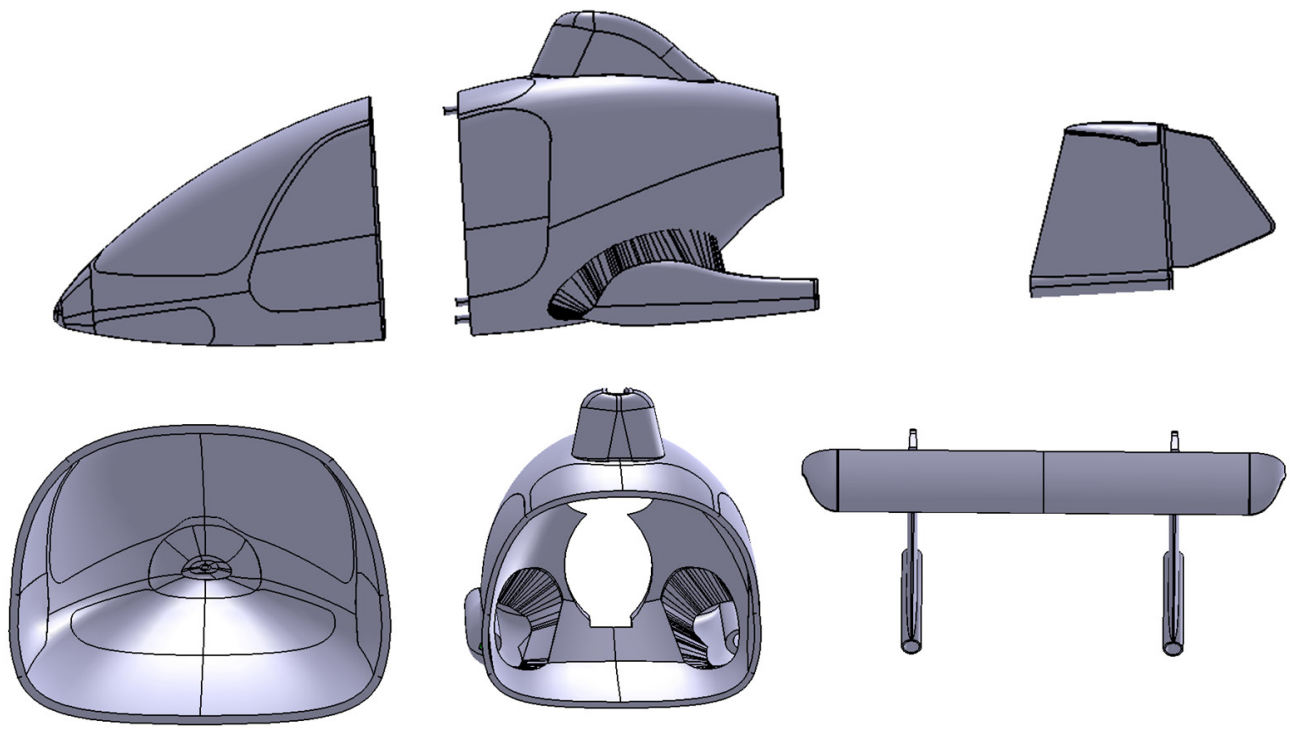

Fig. 3. Sections of the model of the autogyro
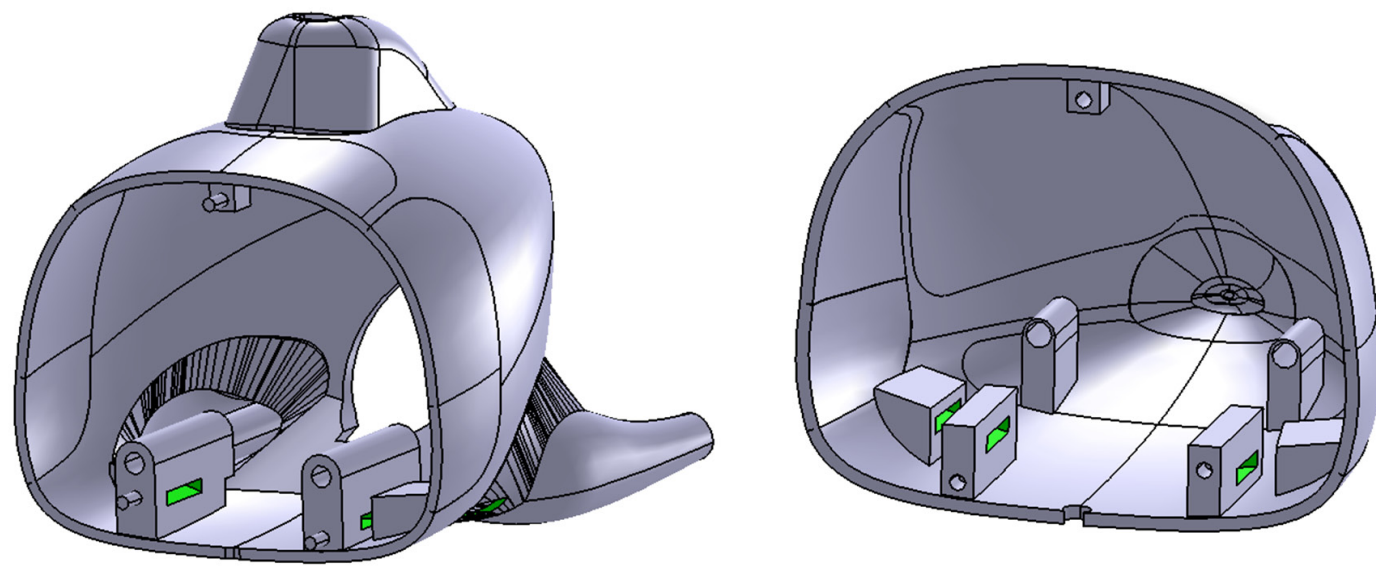

Fig. 4. Fuselage with the mounting and fixing elements

printing was monitored all the time. A single printing layer was $0.0875 \mathrm{~mm}$ thick.

The joined fuselage and the tail were matte acrylic varnished, see Figures 5 and 6.

\section{TEST STAND}

Figure 7 shows the test bench to investigate the visualized airflow around the multirotor. The measurement system is described in detail in [11].

The airflow was visualized in two planes, i.e. a plane of symmetry and a plane parallel to the plane of symmetry and intersecting the axes of the extra horizontal propellers. This paper discusses the results for a plane of symmetry only. This research was performed at a T-1 wind tunnel at the Aviation Institute in Warsaw. This is a closed-circuit wind tunnel with an open test section of $1.5 \mathrm{~m}$ in diameter and $2.2 \mathrm{~m}$ long. The wind tunnel is driven with a $55 \mathrm{~kW}$ electric motor with a 4-bladed constant-speed fan. The drive gives a speed range of $\sim 12 \mathrm{~m} / \mathrm{s}-40 \mathrm{~m} / \mathrm{s}$, regulated by varied the fan blade pitch angle (roughly) and the adjusted releasing flap (precisely) [9].

Figure 8 shows the research object in the wind tunnel measuring chamber and the orientation of the defined planes during our PIV-based visualization.

The measurement area of $660 \mathrm{~mm}$ by $660 \mathrm{~mm}$ (Fig. 9) did not cover the entire frame due to a too small angle of a light angle.

The flow field was investigated for four configurations, i.e. the first one (I) is the fuselage and the tail with the extra propellers of 10" in diameter (propellers are not driven), the second one 


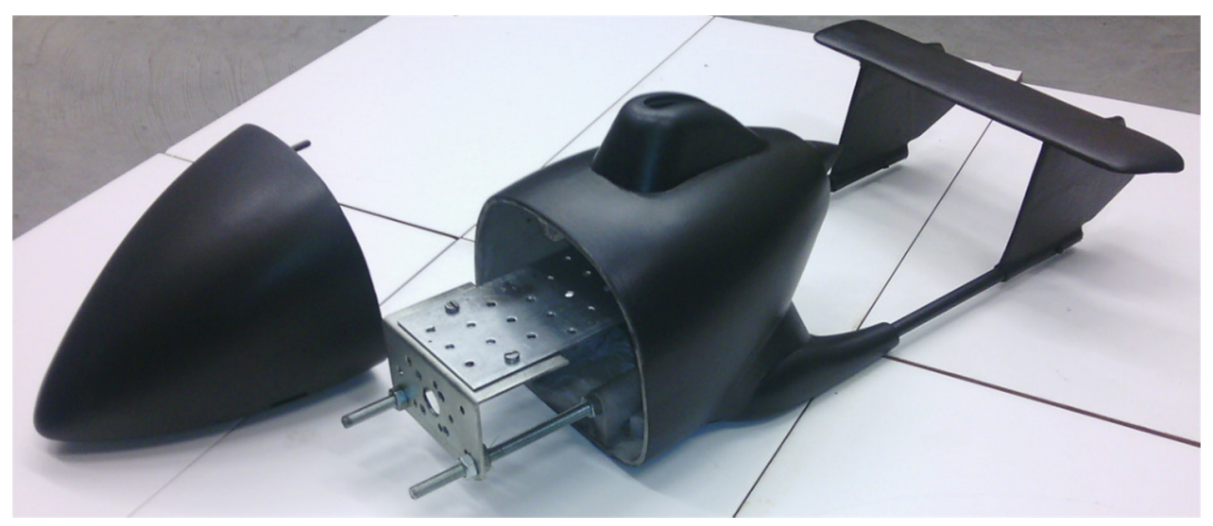

Fig. 5. Fuselage with the interior frame and the mounted tail

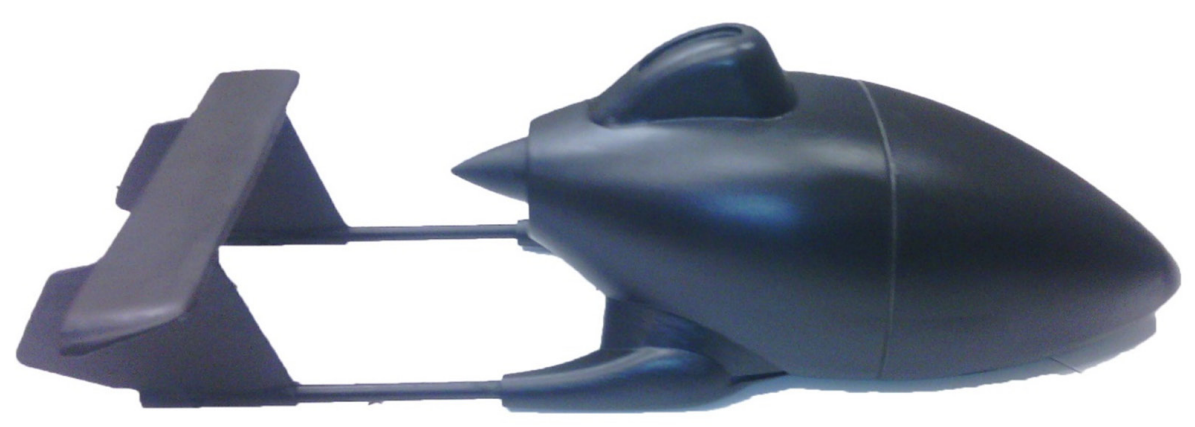

Fig. 6. Varnished fuselage

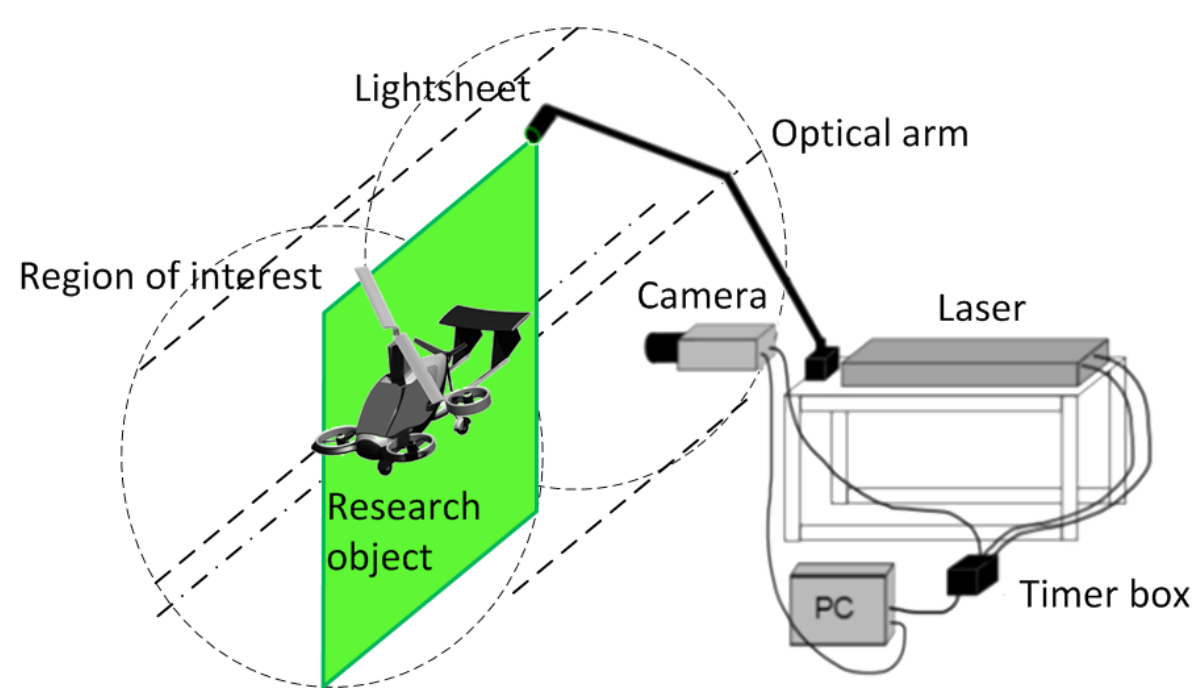

Fig. 7. Schematic diagram of the test bench to visualize the airflow around the research object, self-elaboration, based on [8]

(II) is the fuselage, the tail with propellers of 7" in diameter and an extra push propeller, driven during the measurement. Propeller engines with a vertical vector of thrust were switched off in this configuration. The third configuration (III) has an unpowered rotor in autorotation. While the push propeller operated, the 7" propellers were started. The fourth configuration (IV) is the fuselage and the tail without the push propeller but with the operating main rotor and 10" propellers (Fig. 10).

\section{RESULTS}

Figures 11-14 show the correlation of airflow speed as a function of the $y$-coordinate for the fixed x-coordinates (Fig. 9). 
a)

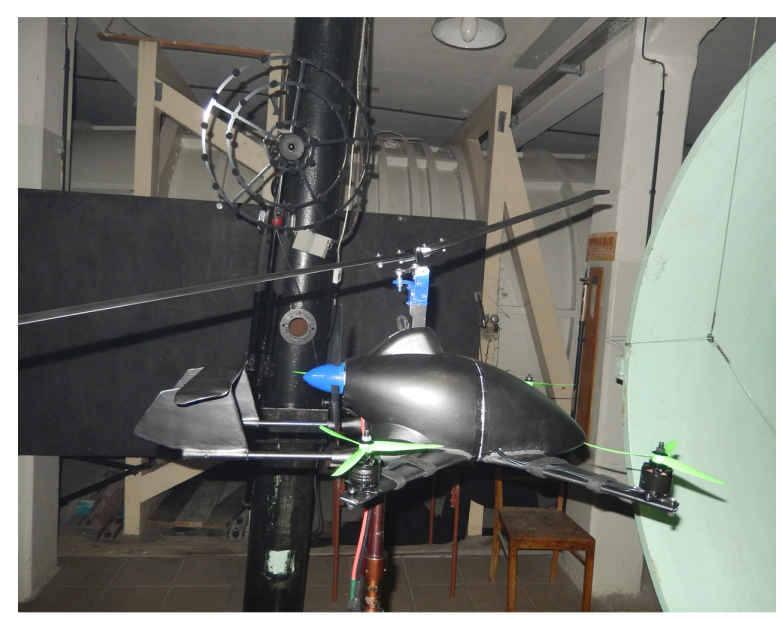

b)

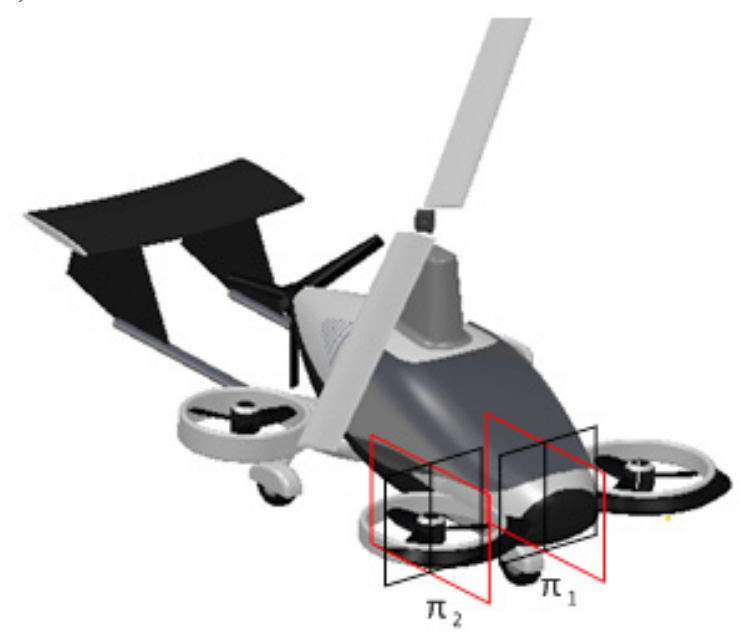

Fig. 8. Research object in the wind tunnel measurement area (left) and the orientation of the defined planes during our PIV-based visualization - a schematic (right)

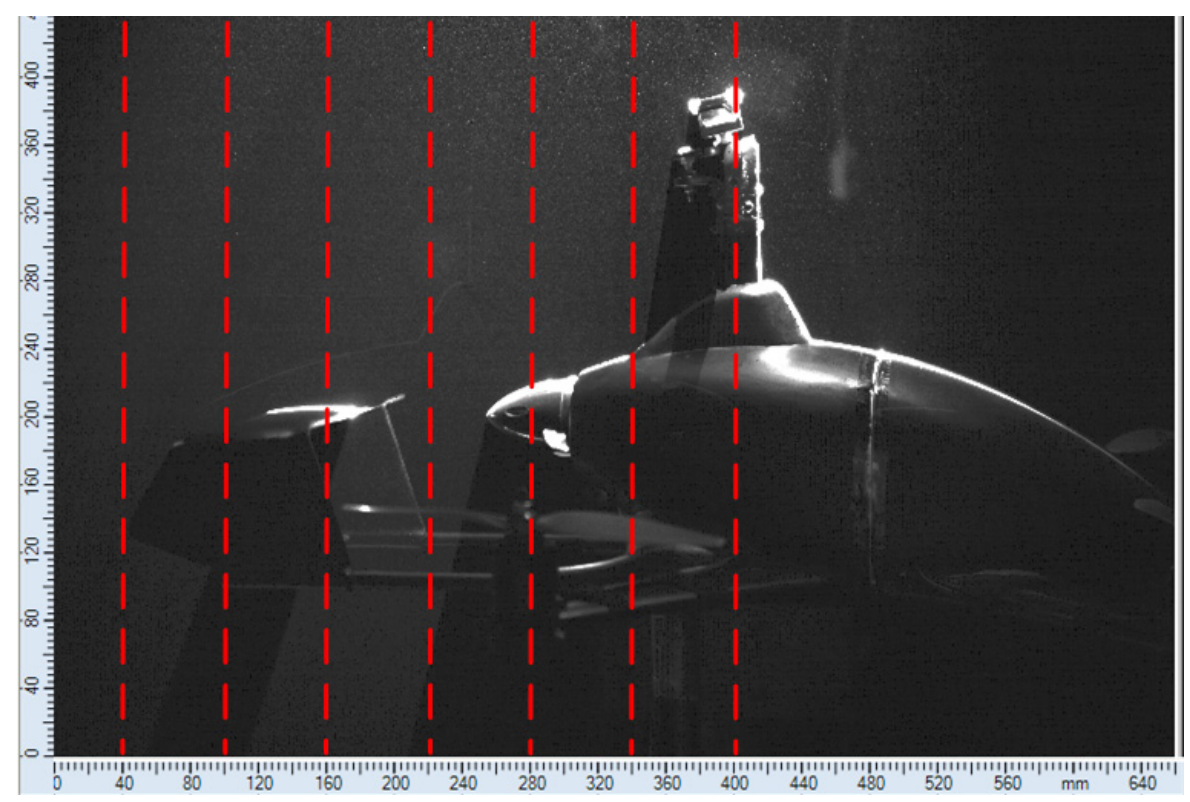

Fig 9. Coordinate system for the measurement area around the aircraft and the cross sections $(\mathrm{x}$ - horizontal axis, $\mathrm{y}-$ vertical axis)

\section{CONCLUSIONS}

The paper investigates the speed distribution around the multirotor at the angle of attack of $0^{\circ}$ and four different configurations. Our investigation covers the visualization of airflow by vector velocity field in the plane of symmetry of the research object. The results enabled speed characteristics depending on the distance from the fuselage. We also observed the impact of the push propeller and main rotor on the speed field around the aircraft. There was investigated the impact of the operating elements of the drive unit on the speed field around the research object. In the first configuration with no operating propelling elements, the airflow speed in the plane of symmetry directly behind the pylon reduces from 12.5 $\mathrm{m} / \mathrm{s}$ to about $3 \mathrm{~m} / \mathrm{s}$ in the $\mathrm{x}$-coordinate $=340 \mathrm{~mm}$. If the distance from the pylon increases, pressure tends to level out and the same happens to speed in the coordinates of the horizontal axis, i.e. $40 \mathrm{~mm}, 100 \mathrm{~mm}, 160 \mathrm{~mm}, 220 \mathrm{~mm}, 280 \mathrm{~mm}$ so speed average values range from $6 \mathrm{~m} / \mathrm{s}$ to $8 \mathrm{~m} / \mathrm{s}$. When the push propeller started in configuration II, the airflow speed increased to about $12.5 \mathrm{~m} / \mathrm{s}$ in the wake $(x=340 \mathrm{~mm})$, whereas it increased up to about $21 \mathrm{~m} / \mathrm{s}$ behind the propeller. The autorotative main rotor and propellers in configura- 
a)

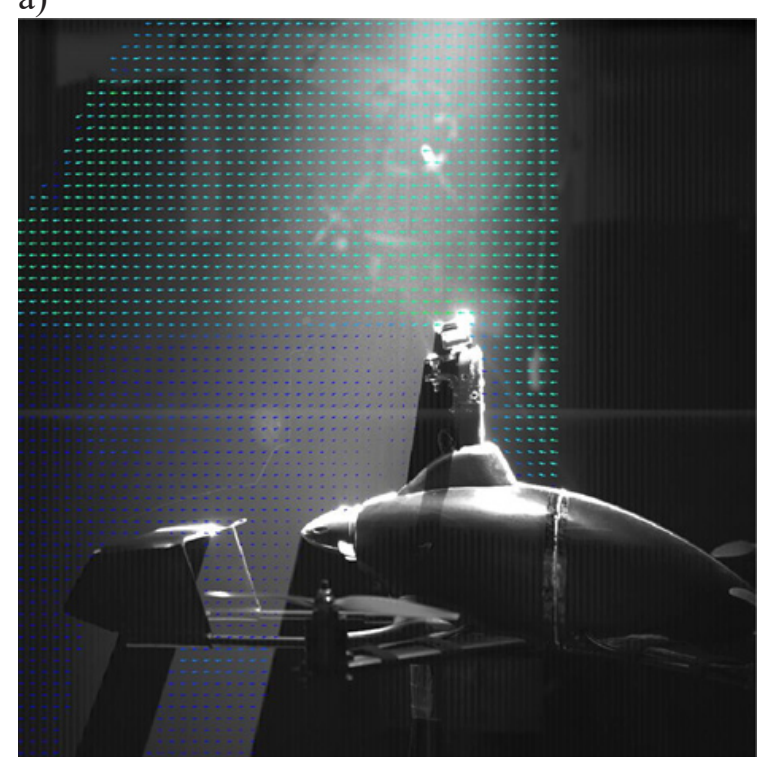

c)

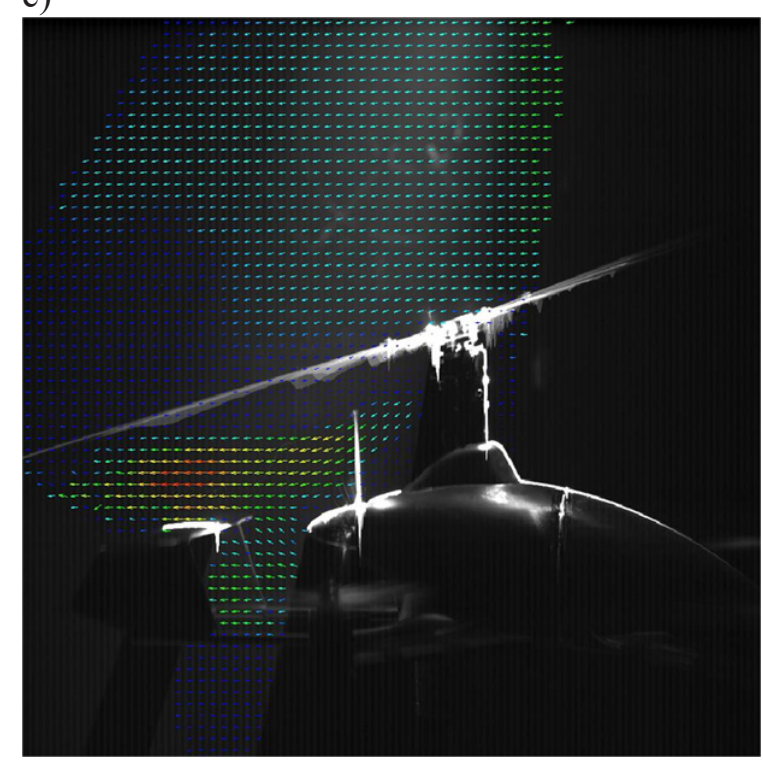

b)

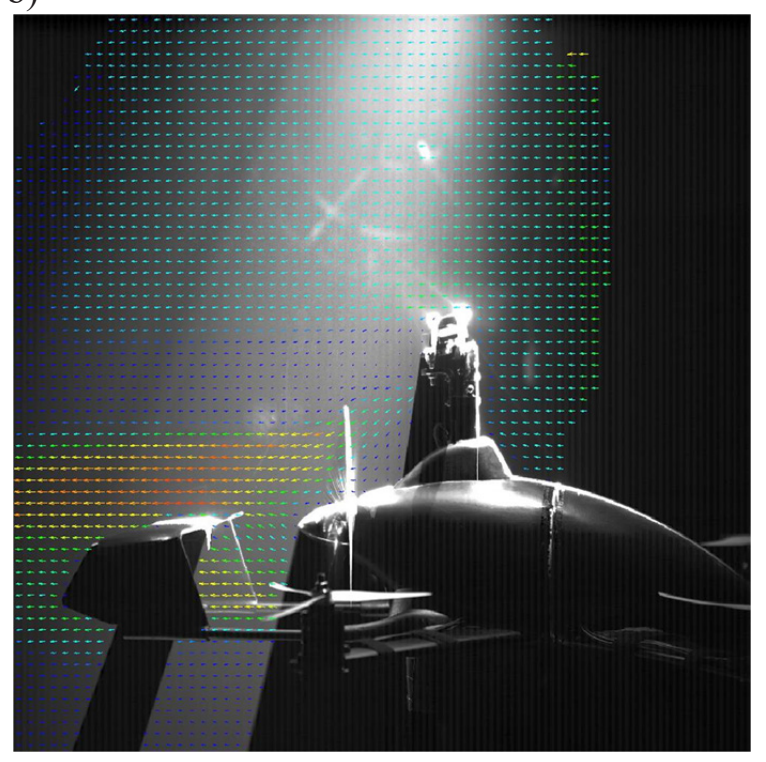

d)

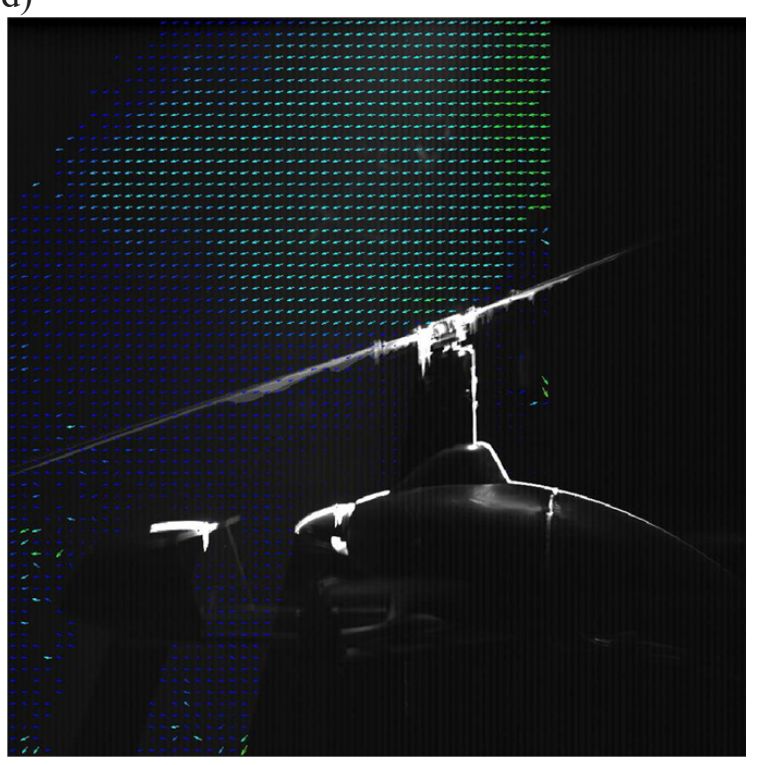

Fig. 10. Four aircraft configurations at an angle of attack $\alpha=0^{\circ}$, with airflow $v=12.5 \mathrm{~m} / \mathrm{s}$

a)

The resultant velocity for $\mathrm{x}=40 \mathrm{~mm}$

$\rightarrow-$ Configuration I_Ost $\rightarrow-$-Configuration II_Ost

$\rightarrow$ Configuration III_Ost $\longrightarrow$ Configuration IV_Ost

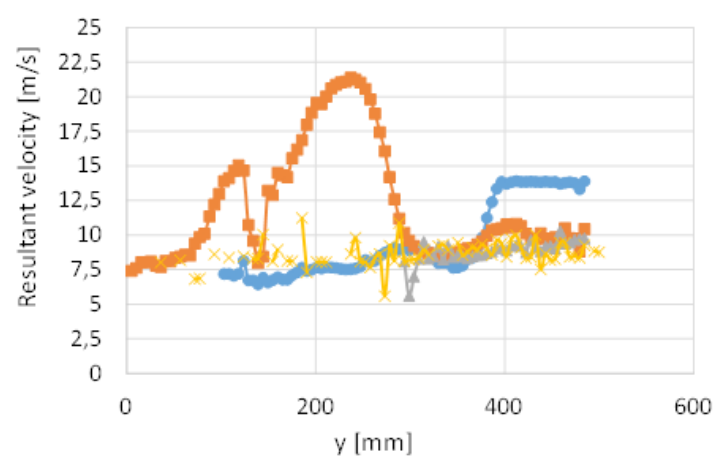

b)

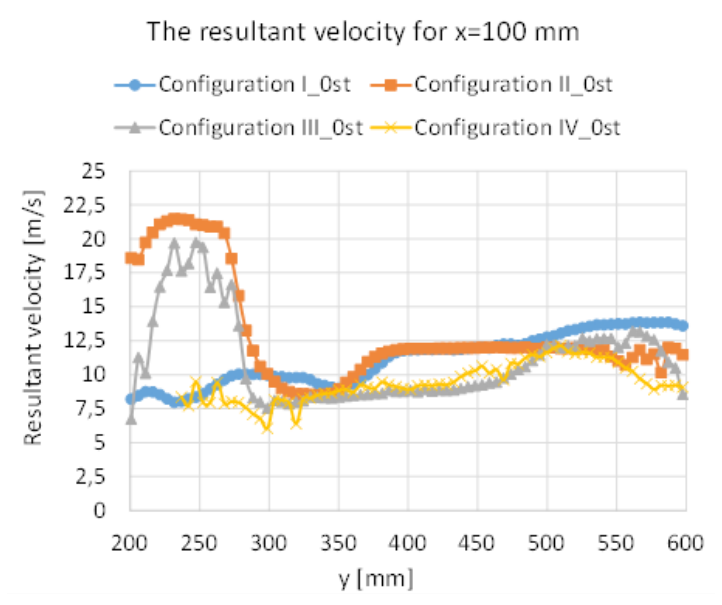

Fig. 11. Correlation of airflow speed as a function of the y-coordinate for the fixed $\mathrm{x}$-coordinate of $40 \mathrm{~mm}$ (left) and $100 \mathrm{~mm}$ (right) 
a)

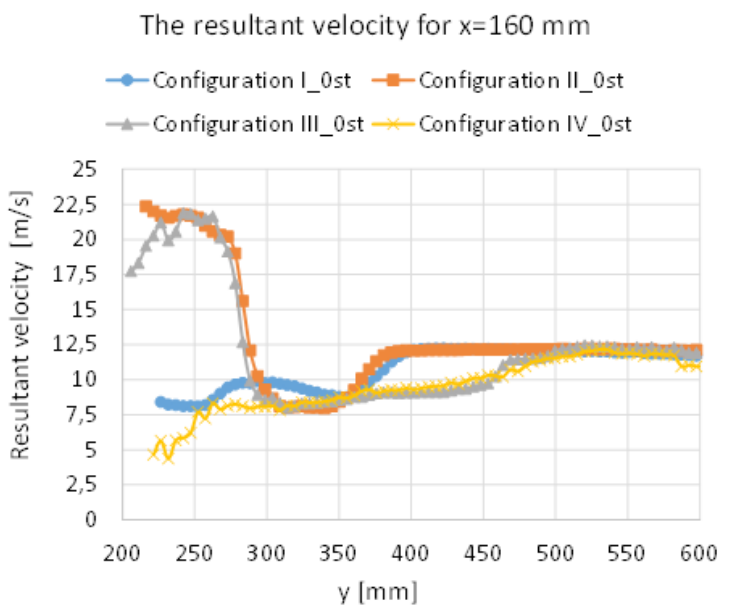

b)

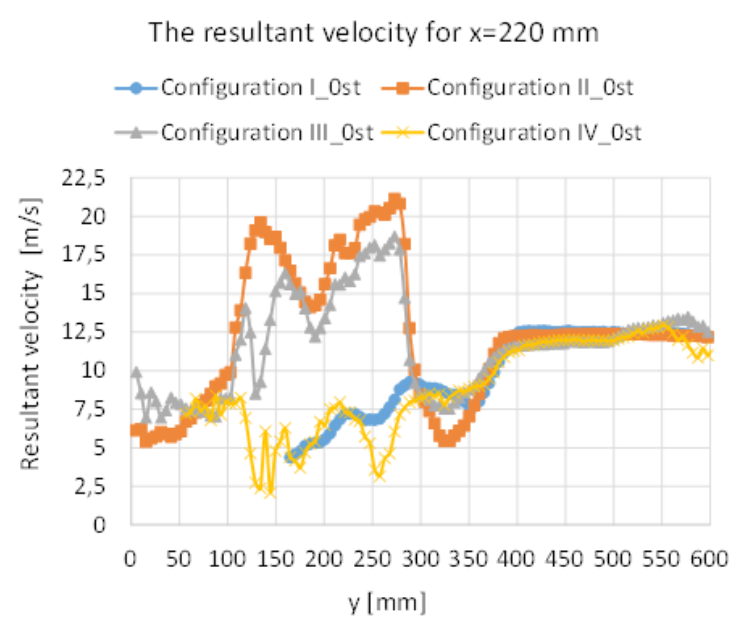

Fig. 12. Correlation of airflow speed as a function of the y-coordinate for the fixed $\mathrm{x}$-coordinate of $160 \mathrm{~mm}$ (left) and $220 \mathrm{~mm}$ (right)

a)

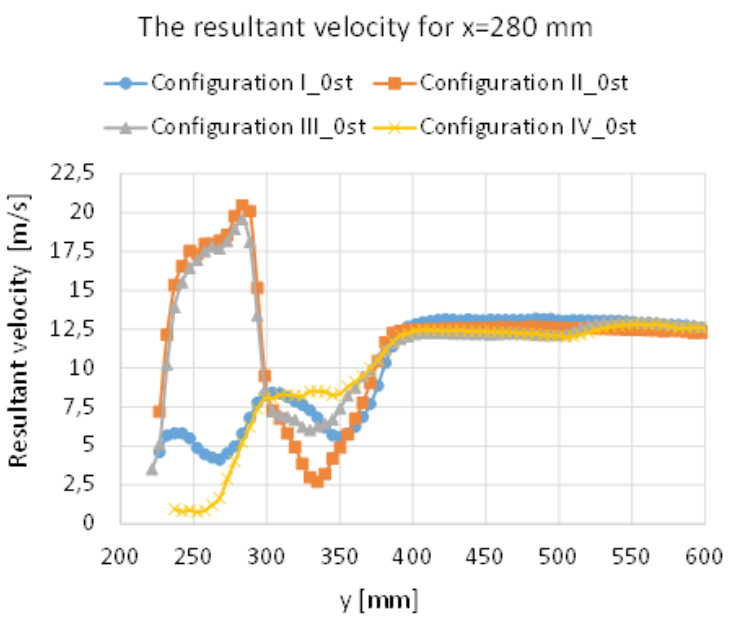

b)

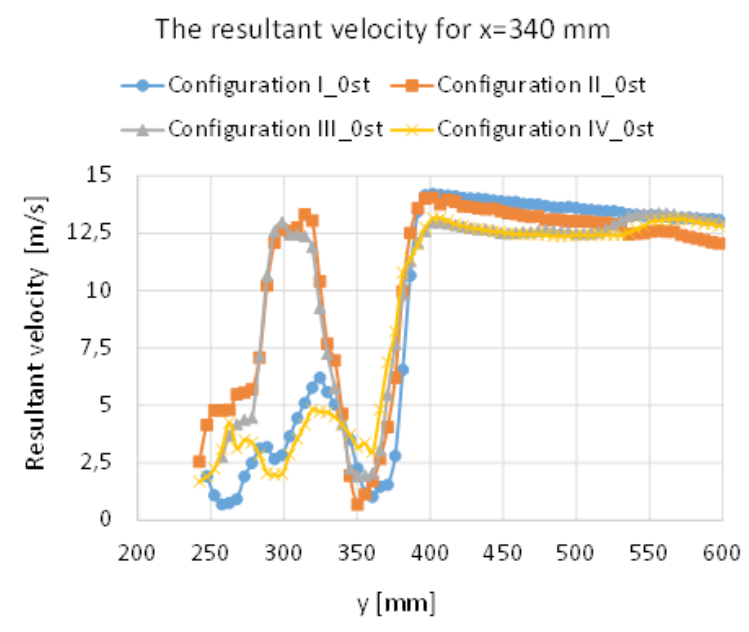

Fig. 13. Correlation of airflow speed as a function of the y-coordinate for the fixed $\mathrm{x}$-coordinate of $280 \mathrm{~mm}$ (left) and $340 \mathrm{~mm}$ (right)

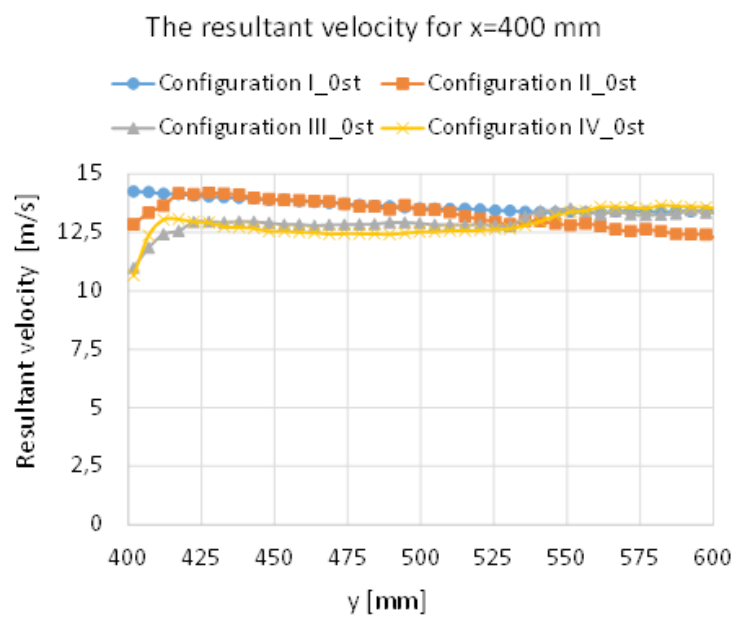

Fig. 14. Correlation of airflow speed as a function of the $\mathrm{y}$-coordinate for the fixed $\mathrm{x}$-coordinate of $400 \mathrm{~mm}$ tion III reduce airflow speed from about $21 \mathrm{~m} / \mathrm{s}$ to $17.5 \mathrm{~m} / \mathrm{s}$ compared to the behind-propeller sphere in configuration II (Fig. 9 and 10).

Our further research shall focus on speed distribution around the multirotor in the next control plane and the other angles of attack. The results of numerical computations shall also be presented and compared.

\section{REFERENCES}

1. Bogdański K., Rodzewicz M., Ruchała P.: Characteristics of locked and free-wheeling ducted fan based on wind tunnel test and CFD analyses. 5th CEAS Air \& Space Conference, 2015. 
2. Chen F.,Liu H., Yang Z., Hu H.: Tracking characteristics of tracer particles for PIV measurements in supersonic flows. Chin J Aeronaut (2017), http:// dx.doi.org/10.1016/j.cja.2016.12.033.

3. Czyż Z., Łusiak T., Magryta P.: Badania Numeryczne CFD wpływu usterzenia na charakterystyki aerodynamiczne wiatrakowca. Prace Instytutu Lotnictwa, 232, 2013, 3-14.

4. CzyżZ., Wendeker M., Raczyński R.: Koncepcja hybrydowego statku powietrznego z napędem wielowirnikowym. Logistyka, nr 6, 2014, 2936-2945.

5. Haertig J, Havermann M, Rey C, George A. Particle image velocimetry in Mach 3.5 and 4.5 shocktunnel flows. AIAAJ, 40(6), 2002, 1056-60.

6. Prouty R. W.: Helicopter Performance. Stability and Control. Malabar, FL: Krieger Publishing Company, 1990, pp. 143-146, 476-477.

7. Pust, O., 2000, PIV: Direct Cross-Correlation compared with FFT-based Cross-Correlation. Proceedings of 10th International Symposium on Applications of Laser Techniques to Fluid Mechanics, Lisbon, Portugal.

8. Ruchała P., Bogdański K., Stryczniewicz W.: Analyses of airflow around ducted fan propulsion system in pusher configuration using PIV method. ICAS 2016.
9. Ruchała P., Stryczniewicz W., Czyż Z., Łusiak T.: Charakterystyki aerodynamiczne kadłuba wiatrakowca dla różnych kątów zaklinowania usterzenia poziomego. Prace Instytutu Lotnictwa, 4(241), 2015, 96-106.

10. Scarano F. Overview of PIV in supersonic flows. Berlin Heidel-berg: Springer; 2007, pp. 445-463.

11. Stryczniewicz, W., Surmacz, K.: Badania eksperymentalne stanu pierścienia wirowego na wirniku nośnym śmigłowca metodą anemometrii obrazowej (PIV). Prace Instytutu Lotnictwa, 235, 2014, $17-27$.

12. Stryczniewicz W.: Zastosowanie metody odwrotnej w celu zwiększenia możliwości pomiarowych metody anemometrii obrazowej (PIV). Prace Instytutu Lotnictwa, Nr 2(243), 2016, 93-107, DOI: $10.5604 / 05096669.1205252$.

13. Stryczniewicz, W.: Algorytm do wyznaczania wektorowego pola prędkości metodą anemometrii obrazowej", Problemy Mechatroniki, 9, 2012, 41-54.

14. Tanahashi, M., Hirayama, T., Taka, S., Miyauchi, T.: Measurement of fin scale structure in turbulence by time-resolved dual-plane stereoscopic PIV. International Journal of Heat and Fluid Flow, 29, 2008, 792-802. 